\title{
Olanzapine approved for the acute treatment of schizophrenia or manic/mixed episodes associated with bipolar I disorder in adolescent patients
}

\author{
This article was published in the following Dove Press journal: \\ Neuropsychiatric Disease and Treatment \\ 9 November 2010 \\ Number of times this article has been viewed
}

\section{Ann E Maloney ${ }^{1,2}$ \\ Linmarie Sikich ${ }^{3}$}

'Maine Medical Center Research Institute, Scarborough, ME, USA; ${ }^{2}$ Department of Psychiatry, Tufts University School of Medicine, Boston, MA, USA; ${ }^{3}$ Department of Psychiatry, University of North Carolina at Chapel Hill, Chapel Hill, NC, USA
Correspondence: Linmarie Sikich Room 254, Medical School Wing D, CB 7160 UNC, I0I Manning Dr, Chapel Hill, NC 275।4-7|60, USA

$\mathrm{Tel}+9199668653 / 9199668655$

Fax+9199668004

Email Isikich@med.unc.edu
Background: Severe and persistent mental illnesses in children and adolescents, such as early-onset schizophrenia spectrum (EOSS) disorders and pediatric bipolar disorder (pedBP), are increasingly recognized. Few treatments have demonstrated efficacy in rigorous clinical trials. Enduring response to current medications appears limited. Recently, olanzapine was approved for the treatment of adolescents with schizophrenia or acute manic/mixed episodes in pedBP.

Methods: PubMed searches were conducted for olanzapine combined with pharmacology, schizophrenia, or bipolar disorder. Searches related to schizophrenia and bipolar disorder were limited to children and adolescents. The bibliographies of the retrieved articles were hand-checked for additional relevant studies. The epidemiology, phenomenology, and treatment of EOSS and pedBP, and olanzapine's pharmacology are reviewed. Studies of olanzapine treatment in youth with EOSS and pedBP are examined.

Results: Olanzapine is efficacious for EOSS and pedBP. However, olanzapine is not more efficacious than risperidone, molindone, or haloperidol in EOSS and is less efficacious than clozapine in treatment-resistant EOSS. No comparative trials have been done in pedBP. Olanzapine is associated with weight gain, dyslipidemia, and transaminase elevations in youth. Extrapyramidal symptoms, neuroleptic malignant syndrome, and blood dyscrasias have also been reported but appear rare.

Conclusions: The authors conclude that olanzapine should be considered a second-line agent in EOSS and pedBP due to its risks for significant weight gain and lipid dysregulation. Awareness of the consistent weight and metabolic changes observed in olanzapine-treated youth focused attention on the potential long-term risks of atypical antipsychotics in youth.

Keywords: early-onset schizophrenia, pediatric bipolar disorder, antipsychotic

The US Food and Drug Administration (FDA) issued an indication for olanzapine in the treatment of adolescents, 13-17 years old, with schizophrenia or acute manic/mixed episodes in bipolar I disorder (BPI) in December 2009. However, the FDA also formally stated that clinicians may "consider prescribing other drugs first in adolescents" given olanzapine's increased potential for weight gain and hyperlipidemia in adolescents compared with adults. This article reviews the presentation and treatment of early-onset schizophrenia (EOS) and pediatric bipolar disorder (pedBP), the pharmacology and kinetics of olanzapine, the evidence supporting olanzapine's efficacy in these two serious mental illnesses among children and adolescents, the safety and tolerability of olanzapine in pediatric patients, and the probable role of olanzapine within the pediatric population compared with the adult population. The 
information presented in this article was gathered through a systematic PubMed review, with searches conducted for olanzapine combined with pharmacology, schizophrenia, or bipolar disorder. Searches related to schizophrenia and bipolar disorder were limited to children and adolescents. The bibliographies of key-retrieved articles were hand-checked for additional relevant studies. Rigorously, controlled data is limited in this population, so observations from nonblinded trials will also be presented. All conclusions are those of the authors and do not reflect specific recommendations of any national organization or government entity.

\section{Early-onset schizophrenia}

The incidence of EOS is not well established with epidemiologic studies. However, a number of geographically limited studies focused on hospital admissions have provided consistent estimates of the incidence in children and adolescents. The illness is very uncommon $(\sim 0.3 / 1000)$ in children younger than 10 years, then increases to approximately $1.3 / 1000$ between ages 10 and 14 years with an even greater increase between 14 and 18 years with incidence rates varying between 2.0 and 5.5/1000. Indeed, at least 5\% of those with schizophrenia become ill prior to 14 years of age and up to $20 \%$ appear to become ill prior to 18 years of age. ${ }^{1-5}$ The peak age of onset is between 15 and 20 years in males and between 15 and 25 years in females. ${ }^{6}$ Modestly more males experience EOS than females ( 1.5 males: 1 female).

Diagnostic criteria for EOS are the same as for adult-onset criteria except that psychotic symptoms must be present prior to age 18 years. However, there are some development differences in detailed characteristics of symptoms. Specifically, youth are more likely to have multimodal hallucinations than adults and frequently personalize their hallucinations giving them names that are frequently stereotyped, such as "Satan," "my guardian angel," or the "monster" or derived from visual characteristics, such as the "man with no skin". They seldom have systematized or bizarre delusional symptoms, though vague paranoia is common. Disorganized thinking is frequently observed. ${ }^{7-10}$ Younger individuals may have difficulty recognizing their symptoms as abnormal and frequently do not complain spontaneously about hallucinations. ${ }^{11}$ Youth who will experience EOS frequently show greater premorbid problems with attention, learning, and socialization than individuals who develop schizophrenia as adults. The onset of symptoms in EOS is most often insidious. ${ }^{12,13}$ Youth with EOS who participate in clinical trials often have more severe psychiatric symptoms, greater neurocognitive deficits, and more pronounced gray matter loss than research participants with adult-onset schizophrenia. ${ }^{14-18}$ Individuals with EOS are much less likely to have a good outcome than individuals with adult-onset schizophrenia, with the majority having poor or very poor outcomes. ${ }^{13,19-21}$

Treatment of EOS has traditionally been based on the pharmacologic treatments used for adult-onset schizophrenia. There is little systematic use of psychotherapeutic strategies in this population. ${ }^{22}$ Efficacy of antipsychotics has been assumed to be generally similar in youth and adults. This view was bolstered by small studies of first-generation antipsychotics (FGAs), including haloperidol, thioridazine, thiothixene, and loxapine that showed relatively high rates of response. ${ }^{9,23,24}$ However, considerable sedation was also observed, and there were concerns about extrapyramidal symptoms (EPS), which appear to be somewhat more prevalent in youth than adults. ${ }^{25}$ In the 1990 s, a pivotal trial was done showing that youth with treatment-resistant schizophrenia had a robust response to clozapine, the prototypic second-generation antipsychotic (SGA) introduced in 1989. ${ }^{26}$ However, significant adverse effects were frequent and limited the use of this agent.

As other SGAs have been introduced and approved for use in adults with schizophrenia over the past 20 years (Table 1), including olanzapine in 1996, clinicians embraced them hoping both for greater efficacy and fewer adverse effects than the FGAs or clozapine. There was particularly great enthusiasm for olanzapine because its pharmacologic profile was most similar to clozapine's and it was less prone to EPS than risperidone, which has more potent dopamine $\mathrm{D}_{2}$ antagonism. Enthusiasm for olanzapine was further increased by a study of olanzapine vs haloperidol in 263 patients with first-episode schizophrenia, who were followed for 2 years. ${ }^{27}$ Although there were no difference in symptom reduction between the two agents in a last observation carried forward analysis, a mixed-model analysis demonstrated an acute advantage for olanzapine in Positive and Negative Syndrome Scale (PANSS) total score, PANSS negative and general symptoms, and a depression rating scale. Results of the 2-year data found that patients treated with olanzapine were significantly more likely to enter remission (olanzapine 57\%, haloperidol 44\%, $P<0.036$ ) and continued treatment for a longer period of time (olanzapine 322 days, haloperidol 230 days, $P<0.0085)$ than those treated with haloperidol. ${ }^{28}$ Perhaps most importantly, the imaging component of this study found that individuals treated with haloperidol experienced significant decreases 
Table I Current FDA indications for second-generation antipsychotics

\begin{tabular}{|c|c|c|}
\hline Drug & Indication & Approval date \\
\hline \multirow[t]{8}{*}{ Aripiprazole } & Schizophrenia in adults & November I5, 2002 \\
\hline & Maintenance treatment of adult schizophrenia & August 28, 2003 \\
\hline & Acute adult manic/mixed BPI & September 29, 2004 \\
\hline & Maintenance treatment of adult BPI & March I, 2005 \\
\hline & Schizophrenia in $13-17$ year olds & October 29, 2007 \\
\hline & Adjunctive treatment in adult major depression & November 16, 2007 \\
\hline & $\begin{array}{l}\text { Acute monotherapy or adjunctive therapy with lithium or valproate in manic/mixed } \\
\text { episodes of } \mathrm{BPI} \text { in } 10-17 \text { year olds }\end{array}$ & February 27, 2008 \\
\hline & Irritability in autism in 6-17 year olds & November 19, 2009 \\
\hline Asenapine & Schizophrenia in adults BPI in adults & August 14, 2009 \\
\hline \multirow[t]{2}{*}{ Clozapine } & Treatment-resistant schizophrenia & September 26, 1989 \\
\hline & Emergent suicidality in schizophrenia or schizoaffective disorder & December 18, 2002 \\
\hline \multirow[t]{8}{*}{ Olanzapine } & Acute psychotic disorders in adults & September 30, 1996 \\
\hline & Manic/mixed in BPI adults & March I7, 2000 \\
\hline & Maintenance treatment in schizophrenia in adults & November 9, 2000 \\
\hline & Adjunctive use with lithium or valproate in acute mania/mixed BPI & July 10, 2003 \\
\hline & Maintenance treatment in adult BPI & January I4, 2004 \\
\hline & $\begin{array}{l}\text { 13-17 year olds with schizophrenia may consider other drugs first due to weight gain and } \\
\text { dyslipidemia }\end{array}$ & \\
\hline & 13-17 year olds with mania/mixed BPI as monotherapy or adjunct to valproate & December 4, 2009 \\
\hline & or lithium may consider other drugs first given weight gain/dyslipidemia & \\
\hline \multirow[t]{6}{*}{ Quetiapine } & Psychotic disorders in adults & September 26, 1997 \\
\hline & Monotherapy or adjunctive therapy in BPI in adults & January I2, 2004 \\
\hline & Major depression associated with BPI in adults & October 20, 2006 \\
\hline & Maintenance treatment in adult BPI as adjunct to lithium or valproate & May 13, 2008 \\
\hline & Treatment of schizoprenia in $13-17$ year olds & December 2, 2009 \\
\hline & Acute treatment of mania/mixed BPI in 10-17 year olds either as monotherapy or adjunctive therapy & \\
\hline \multirow[t]{6}{*}{ Risperidone } & Treatment of schizophrenia in adults & December 29, 1993 \\
\hline & Long-term treatment of schizophrenia in adults & March 3, 2002 \\
\hline & Monotherapy or adjunctive therapy to lithium or valproate in adults with BPI & December 4, 2003 \\
\hline & Irritability in autism in $5-16$ year olds & October 6, 2006 \\
\hline & Schizophrenia in $13-17$ year olds & August 22, 2007 \\
\hline & $\mathrm{BPI}$ in $10-17$ year olds & \\
\hline \multirow[t]{3}{*}{ Ziprasidone } & Schizophrenia in adults & February 5, 200I \\
\hline & Monotherapy in manic/mixed in BPI in adults & August 19, 2004 \\
\hline & Maintenance treatment as adjunct to lithium or valproate in BPI in adults & November 20, 2009 \\
\hline
\end{tabular}

Note: See http://www.fda.gov/Drugs/DrugSafety/PostmarketDrugSafetylnformationforPatientsandProviders/ucm094303.htm.

Abbreviations: FDA, US Food and Drug Administration; BPI, bipolar I disorder.'

in brain gray matter volume, whereas neither those treated with olanzapine nor a healthy control group showed any changes. ${ }^{29}$ Optimism that olanzapine may have particular advantages for treating youth with psychotic symptoms was also heightened with results published from a small pilot study comparing olanzapine, risperidone, and haloperidol in the treatment of psychotic youth aged 8-20 years. ${ }^{30}$ This study in the pediatric population found a modest numeric, but not statistically significant, advantage for olanzapine in the response rate (olanzapine $88 \%$, risperidone $74 \%$, haloperidol $53 \%$ ), premature drop-out (olanzapine $2 / 16$, risperidone $9 / 19$, haloperidol $7 / 15, P=0.058$ ), and time to treatment discontinuation (olanzapine 7.4 weeks, risperidone 6.3 weeks, haloperidol 5.7 weeks). However, the same trial also suggested that adverse events with the SGAs may be more common and more severe in youth than in adults. Proponents of olanzapine also focused on results from the Clinical Antipsychotic Trials of Intervention Effectiveness (CATIE) study in 1,493 adults with chronic schizophrenia. Although there were few clinically significant differences among SGAs and between SGAs and FGAs in the CATIE study, olanzapine had marginally greater benefits as reflected by greater initial reductions in PANSS, greater initial improvements in the Clinical Global Impression (CGI), lower rate of hospitalization due to psychiatric exacerbation, lower discontinuation rates, and longer time to treatment discontinuation. ${ }^{29}$ As discussed in detail later, the Treatment of Early Onset Schizophrenia 
Spectrum Disorders (TEOSS) study did not identify any advantage for olanzapine compared with risperidone or molindone in children and adolescents with schizophrenia, ${ }^{31}$ suggesting a potential difference in olanzapine's efficacy during different stages of schizophrenia.

\section{Pediatric bipolar disorder}

Similar to EOSS, there are few epidemiologic studies that rigorously examine the incidence of pedBP. The primary exception to this is a recent small study done in which 3,021 community subjects (14-24 years of age) in Germany were reassessed 10 years later. ${ }^{32}$ This study found that approximately $1.2 \%$ of the youth had experienced a manic or hypomanic episode by 12 years of age and approximately $4.5 \%$ had experienced a manic or hypomanic episode by 18 years of age. Manic episodes occurred with similar frequency in males and females, whereas hypomanic episodes were about twice as common in females as males and as mania in either gender. Rates dramatically increased during adolescence. Further, $9 \%$ of those with a major depressive episode prior to age 17 years subsequently developed bipolar disorder, which was significantly greater than those with later onset of depression. The incidence of manic and hypomanic episodes in this study is greater than the prevalence of bipolar 1 disorder in adults (4.5\% lifetime and 2.8 annual), ${ }^{33}$ which is typically reported in larger epidemiologic studies, likely due to the expert clinical interviewers used in the German study. In a recent multisite treatment study of 3,658 adults with bipolar disorder, $29 \%$ reported onset before age 13 and $67 \%$ reported onset by age $18 .{ }^{34} \mathrm{~A}$ study of 119 individuals consecutively admitted to a psychiatric hospital in Norway with bipolar disorder found that $13.5 \%$ had onset during childhood and $61.6 \%$ had onset prior to age 20 and that those who reported an affective temperament had earlier onset. ${ }^{35}$ The period of peak onset appears to be in 12 and 22 years of age. ${ }^{32}$ It should be noted that there has been approximately a 40-fold increase in the recognition of bipolar disorder in children and adolescents over the past decade in the US. ${ }^{36}$

Diagnosis of pedBP has been somewhat contentious with many critics arguing that the disorder is misdiagnosed in a large number of youth. The controversy seems related to two major issues.$^{37}$ First, in children and many adolescents, the pattern of cycling within a given episode and the duration of episodes appear quite different between youth and adults. Youth frequently have a large number of cycles or mood swings within a single episode of illness. Often, this cycling can occur multiple times a day even though there may be months without an extended euthymic period that would signal the end of the episode. In contrast, most adults demonstrate a fairly consistent mood state throughout any given episode. In pedBP, a single episode will often last for a very extended period giving the appearance of a chronic condition, whereas in adults, episodes are usually limited to a few weeks. ${ }^{38,39}$ Second, children and, to a lesser extent, adolescents frequently experience mixed states of mania and depression, whereas adults less frequently show such states. The sensitivity and specificity of various individual symptoms of mania and their differential manifestations in other childhood diagnoses are eloquently reviewed by Youngstrom et al. ${ }^{37}$ Further, there are developmental differences within pedBP, with children frequently showing greater comorbidity with attention deficit hyperactivity disorder. Childhood-onset bipolar disorder is associated with greater mood lability, irritability, and hallucinations than adolescent-onset bipolar disorder. However, many highly concerning symptoms, including psychotic symptoms, suicidality, grandiosity, and decreased need for sleep, increase during adolescence, often to a greater extent in those with childhood-onset bipolar disorder than those with adolescent-onset bipolar disorder. ${ }^{40}$ In addition, there is more controversy about the boundaries of the bipolar spectrum in the pediatric population than in the adult population. Criteria for various potential disorders within the spectrum have been most explicitly defined by Leibenluft and colleagues. ${ }^{41}$ These criteria subdivide bipolar NOS (Not Otherwise Specified) into categories in which a sufficient number of criteria are not met, symptoms do not appear to have sufficient duration, irritability is primary mood state, and moods are severely dysregulated in the context of many symptoms of hyperarousal but in the absence of psychotic symptoms or elation. The latter category, called severe mood dysregulation, appears most common and is likely to be highly heterogeneous.

Most of the current longitudinal studies of pedBP involve limited follow-up and focus primarily on rates of remission and relapse. ${ }^{42-46}$ However, adults with childhood-onset bipolar disorder appear to experience significantly worse outcomes, including more rapid relapse, less euthymia, and poorer functioning and quality of life than those with adultonset bipolar disorder. ${ }^{34}$ In addition, rates of suicidality and suicide attempts are particularly high in adolescents with bipolar disorder ( $72 \%-76 \%$ and $31 \%-44 \%$, respectively). ${ }^{47,48}$ Suicidality in bipolar youth appears to be increased in those with psychotic symptoms. ${ }^{49}$

Treatment for pedBP has evolved from treatment of adults with bipolar disorder with specific treatment studies for pedBP limited until the past decade. Until 2007, lithium 
was the only mood-stabilizing agent specifically approved by the FDA for the treatment of acute mania in adolescents. However, this indication does not reflect specific evaluation of the efficacy and safety of lithium in adolescents. Despite this, valproate was probably the most widely used mood stabilizer in the pediatric population until the SGAs were introduced in the 1990s because of its availability in a sprinkle formulation, more favorable therapeutic index (ratio of toxic dose to therapeutic dose), and less onerous sideeffect profile compared to lithium. Carbamazepine was also used to some extent. As other antiepileptic drugs, including oxcarbamazepine, gabapentin, topiramate, and lamotrigine, began to be used in adults, they were embraced for use in the pediatric population because they frequently did not require monitoring of blood levels. Lithium was among the first agents specifically studied in youth. Lithium led to greater reductions in the substance use and improvements in the Clinical Global Impressions Scale than placebo in a sample of 25 adolescents with both bipolar disorder and substance abuse. ${ }^{50} \mathrm{~A}$ subsequent open trial found that lithium, in conjunction with an antipsychotic in nearly $50 \%$ of the cases, led to reduction in acute manic symptoms in approximately two-thirds of adolescents with acute mania and remission in about one-quarter of the participants. ${ }^{51}$ Further, although no placebo-controlled trials of lithium for mania have been completed in pedBP, one study evaluated the rapid discontinuation of lithium by replacement with placebo or continuation of lithium over 2 weeks in youth who had responded to therapeutic doses of lithium for at least 4 weeks. ${ }^{52}$ Surprisingly, more than $50 \%$ of the participants in both the lithium and the placebo groups experienced significant symptom exacerbation. In addition, among adolescents with both psychotic and manic symptoms, long-term treatment with antipsychotics in addition to lithium was generally required to maintain the initial response to treatment. ${ }^{53}$

Other open-label studies in pedBP have described significant responses to valproate and carbamazepine, as well as lithium. ${ }^{54,55}$ However, in many of these trials, the majority of youth were concurrently taking antipsychotics or other mood stabilizers. In the only randomized but open monotherapy trial of mood stabilizers published to date, more than $50 \%$ of the participants did not respond to the initially randomized mood stabilizer though $80 \%$ of these responded to combined treatment with two mood stabilizers. ${ }^{56}$ Studies exploring discontinuation of one mood stabilizer after stabilization on combination treatment support are consistent with the requirement of combination therapy for many youth with bipolar disorder. ${ }^{57}$ Significantly, recent placebo-controlled trials of mood stabilizers published to date have failed to demonstrate efficacy of either oxcarbamazepine or valproate..$^{58,59}$

Antipsychotics were initially used adjunctively in treatment-resistant bipolar disorder in adults. Clozapine appeared particularly effective. Subsequently, other second-generation agents were studied as a treatment of all phases of bipolar disorder, particularly risperidone and olanzapine. Initially, antipsychotics were used as adjunctive treatment to mood stabilizers and appeared to have increased benefit with no major tolerability issues. ${ }^{60} \mathrm{~A}$ blinded, placebo-controlled trial of quetiapine adjunctive therapy demonstrated significantly greater reduction in mania scores and greater response rate than valproate monotherapy. ${ }^{61}$ An open-label trial of olanzapine monotherapy was also very promising. ${ }^{62}$ Subsequently, a double-blind trial comparing quetiapine with valproate demonstrated superior response and remission rates with quetiapine even though reductions in mean mania scores did not differ. ${ }^{63}$ Since that time, placebo-controlled trials of each of the atypical antipsychotics other than clozapine - olanzapine, ${ }^{64}$ aripiprazole, ${ }^{65}$ risperidone,${ }^{66}$ and quetiapine ${ }^{67}$ - have found that each active agent reduced the Young Mania Rating Scale (YMRS) ${ }^{68}$ score to a significantly greater extent than placebo over 3 weeks among youth experiencing acute manic/mixed episodes. Based on these results, risperidone and aripiprazole were approved for the acute treatment of mixed and manic episodes of bipolar disorder in youth of 10-17 years old, and olanzapine and quetiapine were approved in adolescents. There has also been one small, double-blind pilot study that failed to show any advantage for quetiapine over placebo in the treatment of depression within pedBP ${ }^{69}$ Notably, a large National Institute of Mental Health (NIMH)-sponsored comparative trial of risperidone, valproate, and lithium has been recently completed and should be reported soon. In summary, there is evidence for significant benefit from antipsychotics in the treatment of mixed and manic states in youth and a lack of efficacy of valproate and oxcarbamazepine. There is no empiric evidence yet of an effective treatment for depression or relapse prevention in youth with bipolar disorder.

\section{Olanzapine pharmacology and pharmacokinetics}

Olanzapine is a thienobenzodiazepine analog that binds to a large number of neurotransmitter receptors, including the dopamine $\mathrm{D}_{1}, \mathrm{D}_{2}$, and $\mathrm{D}_{4}$ receptors, serotonin $5-\mathrm{HT}_{2 \mathrm{~A}}$, $5-\mathrm{HT}_{2 \mathrm{C}}, 5-\mathrm{HT}_{6}$, and 5- $\mathrm{HT}_{3}$ receptors, histamine $\mathrm{H}_{1}$ receptor, muscarinic receptors, $\alpha$ - and $\beta$-adrenergic receptors, $\gamma$-amino butyrate $(\mathrm{GABA})_{\mathrm{a} 1}$ receptor, and the benzodiazepine binding sites..$^{70}$ Its binding profile is more similar to clozapine's 
than any other atypical antipsychotic. Olanzapine's antipsychotic and mood-stabilizing effects are likely the result of potent antagonism at dopamine and serotonin receptors, with affinity constants ranging from $4 \mathrm{nM}$ to $31 \mathrm{nM}$. It also binds with high affinity to $H_{1}$ and $M_{1}$ receptors. The drug binds with moderate affinity to $5-\mathrm{HT}_{3}$ and $\mathrm{M}_{2-5}$ receptors and binds weakly to GABA, benzodiazepine binding sites, and $\beta$-adrenergic receptors. It is also likely that olanzapine regulates various signaling pathways within the brain, including the extracellular signal-related kinases (ERK1/2), particularly with long-term treatment. ${ }^{71}$ Developmental differences in the binding profile of olanzapine have not been examined to our knowledge. Olanzapine's metabolic adverse effects have been hypothesized to relate to its histaminergic binding profile. ${ }^{72,73}$ In addition, olanzapine-associated weight gain has been linked to genetic variations in the $5-\mathrm{HT}_{2 \mathrm{~A}}, 5-\mathrm{HT}_{2 \mathrm{C}}$, and $\beta_{3}$-adrenergic receptor, leptin, and the G-protein $\beta_{3}$ subunit genes. ${ }^{74-76}$ The anticholinergic side effects are likely related to the muscarinic antagonism and the orthostatic hypotension related to antagonism at $\alpha$-adrenergic receptors.

Olanzapine is well absorbed after oral administration and reaches maximal levels in about 5 hours in adults. Eating does not appear to affect olanzapine's bioavailability. It is excreted in the urine (65\%) and feces $(35 \%)$ over the course of approximately 7 days. ${ }^{77}$ It is metabolized extensively within the liver undergoing glucuronidation (to yield the primary metabolic products), allylic hydroxylation, oxidation, and dealkylation. Oxidation occurs primarily via the CYP1A2 cytochrome P450 enzyme (Figure 1). ${ }^{78}$

Levels are affected by smoking (leading to $\sim 30 \%$ reduction in plasma level), gender (women have $\sim 85 \%$ increased plasma levels), carbamazepine (decreased plasma levels), and fluvoxamine and other selective serotonin reuptake inhibitors (SSRIs) (increased plasma levels). ${ }^{79-84}$ The elimination half-life ranges from about 27 hours in smokers to 37 hours in nonsmokers. Plasma levels of olanzapine appear to increase slowly over a period of months with a slightly slower time course in women compared with men. ${ }^{81,85}$ There are no significant differences that appear in bioavailability or half-life of oral tablet and the orally disintegrating form of olanzapine. ${ }^{86}$

In general, the pharmacokinetics of olanzapine are similar in youth and adults. ${ }^{87,88}$ Adolescents experience considerable intra-individual variability across time despite stable dosing, which appears somewhat greater in adolescents than adults. ${ }^{85,89}$ The concentration-to-dose ratio of olanzapine appears generally linear. ${ }^{78}$ However, adolescents appear to have a higher $(\sim 34 \%)$ concentration-to-dose ratio than adults even after adjustment for weight. ${ }^{90}$

\section{Olanzapine efficacy in EOS}

The first report of olanzapine treatment in youth with schizophrenia was an open trial done in eight youth with childhood-onset, who had not responded to prior trials with antipsychotics other than clozapine. ${ }^{91}$ In this study, there was modest improvement in overall symptoms and negative symptoms but no significant change in positive symptoms. A comparison group of 15 treatment-resistant youth exposed to clozapine demonstrated greater benefits only after 6 weeks of treatment. In a trial of 15 children younger than 13 years of age, 10 showed moderate or marked improvements in psychotic symptoms. ${ }^{92}$ However, all patients who had been previously exposed to antipsychotics did not improve. In contrast, an open-label study of 9 other treatmentresistant children found significant improvements at 12 weeks from baseline in all symptom domains and found that eight of the children sustained improvements over the course of 1 year. ${ }^{93}$ However, two double-blind studies comparing clozapine and olanzapine in youth with treatment-resistant schizophrenia had similar findings to the initial report. ${ }^{94,95}$ In each of these trials, clozapine resulted in greater reductions in negative symptoms and, in the most recent trial, greater response rates.

Olanzapine has also been tested in youth with schizophrenia, who are not treatment resistant. The initial open trials for these youth were done in 2003, and included 20 youth (6-15 years old) and 16 adolescents (12-17 years old) respectively. ${ }^{96,97}$ Both trials showed significant improvements in symptoms, illness severity, and function within 6-8 weeks of initiating treatment. However, improvements in negative symptoms were reported to occur later in the trial that included children and adolescents. ${ }^{97}$ In the Ross trial, 74\% of the youth were considered responders and retained that response status after 1 year of treatment. A similar response rate has been achieved in other open-label trials including a large 6-week trial with an additional 18-week follow-up in 96 adolescents. ${ }^{98,99}$

Subsequently, olanzapine was openly compared with risperidone and haloperidol in physicians' choice (nonrandomized) treatment of 43 adolescents with schizophrenia. ${ }^{100}$ There were no apparent differences in antipsychotic efficacy between the three treatments with significant benefit within 4 weeks of starting treatment. However, haloperidol was associated with greater emergence of depressive symptoms. A more recent trial that involved 16 adolescents with psychotic symptoms treated with olanzapine, 50 treated with risperidone, and 18 treated with quetiapine also failed to detect differences between the antipsychotic efficacy of the agents 
<smiles>Cc1cc2c(s1)Nc1ccccc1N=C2N1CCN(C)CC1</smiles><smiles>Cc1cc2c(s1)Nc1ccccc1N=C2N1CC[N+](C)(C)CC1</smiles>

$\mathrm{N}$-oxide

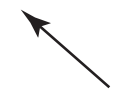

4'-N-glucuronide<smiles>Cc1cc2c(s1)Nc1ccccc1N=C2N1CCN(C)CC1</smiles>

N-desmethyl<smiles>[Y]C1CCCCC1N1CCNCC1</smiles>

$\mathrm{N}$-desmethyl-2-hydroxymethyl

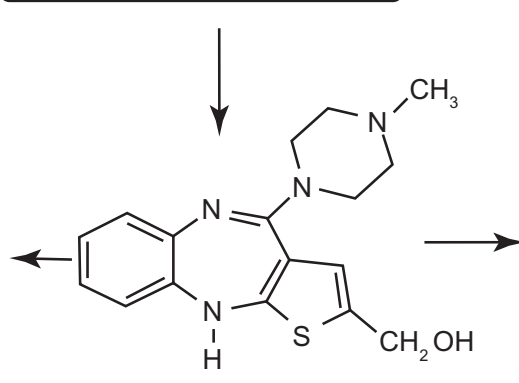

2-hydroxymethyl<smiles>[Y][Y]([Y])([H])C1=Nc2ccccc2Nc2sc(C(=O)O)cc21</smiles>

N-desmethyl-2-carboxy

Figure I Metabolism of olanzapine. The chemical structure and metabolism of olanzapine are shown. Copyright (c) 1997. Modified with permission from Kassahun K, Mattiuz E, Nyhart E Jr, et al. Disposition and biotransformation of the antipsychotic agent olanzapine in humans. Drug Metab Dispos. 1997;25(I):8I-93. ${ }^{77}$

at 6 months when baseline psychopathology scores were included as a covariate in the analysis. ${ }^{101}$ However, olanzapine consistently showed the greatest number of reductions in all types of psychotic symptoms. A double-blind, randomized trial of acute psychotic symptoms in 50 youth with either affective or schizophrenic psychoses also failed to show statistically significant differences between treatments. ${ }^{30} \mathrm{In}$ this study, the olanzapine group showed the greatest response rate ( $88 \%$ compared with $74 \%$ for risperidone and $53 \%$ for haloperidol) and longest duration of treatment. However, the numeric superiority of olanzapine may have partially reflected the preponderance of youth with affective psychoses (69\%) in the olanzapine group in contrast with the other two groups where schizophrenic diagnoses were more common. A larger $(\mathrm{n}=116)$, placebo-controlled, randomized trial comparing olanzapine $(\mathrm{n}=34)$ with risperidone $(\mathrm{n}=41)$ and molindone $(n=40)$ exclusively in youth with EOS, known as the TEOSS trial, again found no statistically significant or numeric differences in symptom reduction between the agents. ${ }^{31,102}$ However, in contrast to the earlier study, olanzapine treatment was sustained for a numerically shorter period, and numerically fewer participants treated with olanzapine responded than those treated with the other two agents (olanzapine: $34 \%$; risperidone: $46 \%$, molindone: $50 \%$ ). 
One double-blind, placebo-controlled trial of olanzapine has been done in adolescents 13-17 years old with schizophrenia. ${ }^{103}$ In this international multisite trial, 72 youth were treated with olanzapine and 35 with placebo. Olanzapine treatment led to much greater and highly statistically significant improvements in the CGI Severity score $(P=0.004)$, the Brief Psychiatric Rating Scale for Children (BPRS-C) $)^{104,105}$ $(P=0.003)$, the PANSS total score $(P=0.005)$, and positive symptom scale $(P=0.002)$, but not negative symptoms. However, a reviewer at the FDA raised concerns about the study because the positive results of the study were primarily driven by the Russian sites not the US sites. ${ }^{106}$ Although the BPRS-C symptom reduction seen with olanzapine was similar in both sites (US: -21 , Russia: -17 ), there were dramatic differences in the magnitude of reduction with placebo (US: -15 ; Russia: -3 ), resulting in markedly different changes in the $P$ value (US: $P=0.258$; Russia: $P=0.003$ ). Importantly, an FDA audit of two Russian sites found no concerns about the conduct of the study. The FDA Director of the Division of Psychiatry Products, Dr. Thomas Laughren, believed that these differences between sites probably reflected differences in the availability of care for youth with schizophrenia between the two countries and greater heterogeneity of the study population at US sites and also believed that olanzapine should be approved in adolescent schizophrenia.

\section{Olanzapine efficacy in pedBP}

Olanzapine was initially reported to be useful for treating mania and mixed states in an 8-week, open-label prospective study of 23 youth aged 5-14 years old. ${ }^{62}$ There was a highly significant improvement in the $\mathrm{YMRS}^{107}(-19.0, P<0.001)$ and overall response rate (defined as $\geq 30 \%$ reduction in YMRS and CGI-Severity score of mild or less severe) was $61 \%$. Subsequently, DelBello and colleagues ${ }^{108}$ examined the effects of olanzapine treatment on brain neurochemistry using proton spectroscopy in 19 adolescents with mania, who were scanned prior to beginning treatment and on days 7 and 28 of treatment. Ten healthy control adolescents were scanned to assess normal variability in brain metabolites over 4 weeks. Ten $(58 \%)$ of the participants had remission of symptoms. All participants showed increases in ventral prefrontal choline. However, those with remission showed significant increases in medial ventral prefrontal $N$-acetyl aspartate within 7 days of treatment $(P=0.05)$ and had increased baseline levels of ventral prefrontal choline compared with nonremitters $(P<0.001)$. Because $\mathrm{N}$-acetyl aspartate is believed to reflect neuronal vitality, this finding suggests potential beneficial changes in brain structure among some adolescents whose mania is treated with olanzapine. The only randomized, placebo-controlled trial of olanzapine for the treatment of manic and mixed states in adolescents (13-17 years old) was conducted by Eli Lilly. ${ }^{64}$ In that study, 107 youth were treated with olanzapine and 54 with placebo for 3 weeks. The olanzapine group showed significantly greater reduction in the YMRS than the placebo group (olanzapine: -17.7, placebo: $-10.0, P<0.001)$. Olanzapine also led to dramatically higher response and remission rates than placebo (olanzapine: $48.6 \%$ and $35.2 \%$, placebo: $22.2 \%$ and $11.1 \%$, $P=0.002$ and $P=0.001$, respectively). We are unaware of any trials that have compared the efficacy of olanzapine and other mood-stabilizing agents in the pediatric population.

\section{Olanzapine safety and tolerability in youth}

Despite the evidence supporting the efficacy of olanzapine in EOS and pedBP, concerns about excessive weight gain with olanzapine emerged early. As olanzapine was used more frequently in youth, additional concerns about metabolic abnormalities, liver function abnormalities, sedation, and prolactin elevations emerged. Subsequently, the safety and tolerability of olanzapine in the pediatric population have been examined in comparison to adults treated with olanzapine. An early postmarketing surveillance study examined the database for olanzapine through March 31, 2000, linked it with patient exposure estimates during the same period provided by Eli Lilly, and divided the analysis into children (birth to 9 years), adolescents (10-19 years), and adults (20 years and older). ${ }^{109}$ The study found that extrapyramidal syndrome complaint risks were similar across development, and tardive dyskinesia complaint risks were comparable in adolescents and adults. Overrepresented complaints in children included weight gain, liver function abnormalities, sedation and tardive dyskinesia. Overrepresented complaints in adolescents included weight gain, liver function abnormalities, sedation, and prolactin increases. A more recent analysis done by Eli Lilly compared the weight and metabolic data from 454 adolescents aged 13-17 years old exposed to olanzapine (primarily under open conditions) for as long as 32 weeks to the pooled weight data from 7,847 adults treated with olanzapine for up to 32 weeks and pooled metabolic data from adults from four trials. ${ }^{107}$ The adolescents experienced more frequent and severe weight gain than the adults $(>7 \%$ weight gain in $65.1 \%$ of adolescents and $35.6 \%$ of adults, $P<0.001$; mean weight gain $7.4 \mathrm{~kg}$ in adolescents and $3.2 \mathrm{~kg}$ in adults, 
$P<0.001)$. Adolescents were also much more likely to develop hyperprolactinemia (adolescents: $55.5 \%$, adults: $29.0 \%, P<0.001)$. However, in contrast, adults had more adverse metabolic changes than the adolescents with $11.8 \%$ of adults and 3\% of adolescents moving from normal or impaired glucose to high glucose $(P<0.001)$, and $31 \%-38 \%$ of adults compared with $17 \%-21 \%$ of adolescents developed borderline dyslipidemias $(P<0.001$ for all). This likely reflects other lifestyle and metabolic problems including lower insulin reserves in the adults.

Thelargestandmostdefinitive datareview ofolanzapine'ssafety and tolerability in adolescents, pools all six Eli Lilly-sponsored trials of olanzapine in a total of 179 youth studied under placebocontrolled conditions for up to 6 weeks and 454 youth exposed to olanzapine (primarily under open conditions) for as long as 32 weeks. ${ }^{110}$ There have also been some trials that compared adverse effects observed in youth treated with olanzapine or other antipsychotics, including data between 45 and 52 weeks of exposure. . $^{30,31,93,101,102,111-115} \mathrm{We}$ will examine each of the main adverse effects observed with olanzapine separately.

\section{Weight gain}

In the Eli Lilly placebo-controlled adolescent database, youth gained $3.9 \mathrm{~kg}$ when treated with olanzapine compared with $0.2 \mathrm{~kg}$ when treated with placebo $(P<0.001)$. In the adolescent-exposure database, the overall weight gain was $7.4 \mathrm{~kg}$, with nearly two-thirds gaining more than $7 \%$ of their baseline weight and a 13.3 percentile increase in body mass index (BMI), which is a more appropriate measure of increased size in youth. Overall, $4 \%$ of adolescents withdrew from treatment because of weight gain. In examining the time course of weight gain, there appears a marked reduction in the slope of weight gain after 4 weeks of treatment. ${ }^{110}$ Similar findings of rapid weight gain followed by slower weight gain have been observed in other trials. ${ }^{96,102,111,114}$

In the comparative studies, olanzapine consistently demonstrated the greatest weight gain both acutely and with more extended use as summarized in Table 2. In almost all cases, it has led to significantly more weight gain than other antipsychotics with a very high level of significance. Further, in contrast with the adult literature, studies that directly compare clozapine and olanzapine treatment in youth have found that clozapine increases weight to a lesser or equivalent extent than olanzapine does..$^{95,113,114}$ One study examining 65 youth treated with olanzapine, clozapine, or risperidone found elevations in parents' and patients' pretreatment BMIs. Female gender and younger age when treated were associated with the magnitude of antipsychotic-associated weight gain independent of medication. Further, individuals with low pretreatment BMIs initially show more rapid weight gain than their heavier peers even though total weight gain with treatment is less. ${ }^{116}$

\section{Glucose metabolism}

In the Eli Lilly placebo-controlled database, olanzapinetreated youth showed a $3.6 \mathrm{mg} / \mathrm{dL}(0.2 \mathrm{mmol} / \mathrm{L})$ increase in fasting glucose, whereas placebo-treated youth showed a similarly sized decrease. Although not clinically significant, this finding was highly statistically significant $(P<0.001)$. Further, $3 \%$ of adolescents in the exposure database moved from normal or borderline glucose levels into the diabetic range. ${ }^{110}$ Increases in fasting glucose with olanzapine treatment ranging from 0.6 to $10 \mathrm{mg} / \mathrm{dL}$ have been reported in several other pediatric trials (Table 2) ${ }^{30,31,95}$ A study of 45 antipsychotic- naïve youth treated with olanzapine found significant increases in glucose, insulin, and insulin resistance (measured with homeostasis model assessment-insulin resistance [HOMA-IR]) with $P$ values between 0.02 and $0.03 .{ }^{115}$ There have also been multiple case reports of youth developing diabetes during olanzapine treatment. ${ }^{117-120}$ It is clear that youth are less likely to rapidly develop diabetes as a consequence of olanzapine treatment than adults because most teens have large insulin reserves. It is not yet clear to what extent these increases in glucose persist with sustained treatment.

\section{Lipid metabolism}

In the Eli Lilly database, youth treated with olanzapine showed increases in total cholesterol and triglycerides relative to their peers treated with placebo [cholesterol $11.7 \mathrm{mg} / \mathrm{dL}(0.03 \mathrm{mmol} / \mathrm{L})$ compared to no change and triglycerides $26.7 \mathrm{mg} / \mathrm{dL}(0.03 \mathrm{mmol} / \mathrm{L})$ compared to a decrease of $8.9 \mathrm{mg} / \mathrm{dL}(-0.1 \mathrm{mmol} / \mathrm{L}) ; P=0.002$ and $P=0.007$, respectively]. Those in the exposure database showed identical changes. Approximately one-fifth of the patients developed borderline elevations in total cholesterol ( $>200$ and $<240 \mathrm{mg} / \mathrm{dL}$ ), low-density lipoproteins (LDL cholesterol $>130$ and $<160 \mathrm{mg} / \mathrm{dL}$ ), and triglycerides ( $>150$ and $<200 \mathrm{mg} / \mathrm{dL}$ ), and $17.8 \%$ developed hypertriglyceridemia. ${ }^{110}$ Interestingly, changes in lipid levels were slightly less in the study of antipsychotic-naïve youth ranging from $11.5 \mathrm{mg} / \mathrm{dL}$ for LDL cholesterol to $24.3 \mathrm{mg} / \mathrm{dL}$ for triglycerides with all $P$ values less than $0.004 .{ }^{115}$ Similar changes have been reported in other small 
Table 2 Reported weight and metabolic changes with pediatric olanzapine treatment

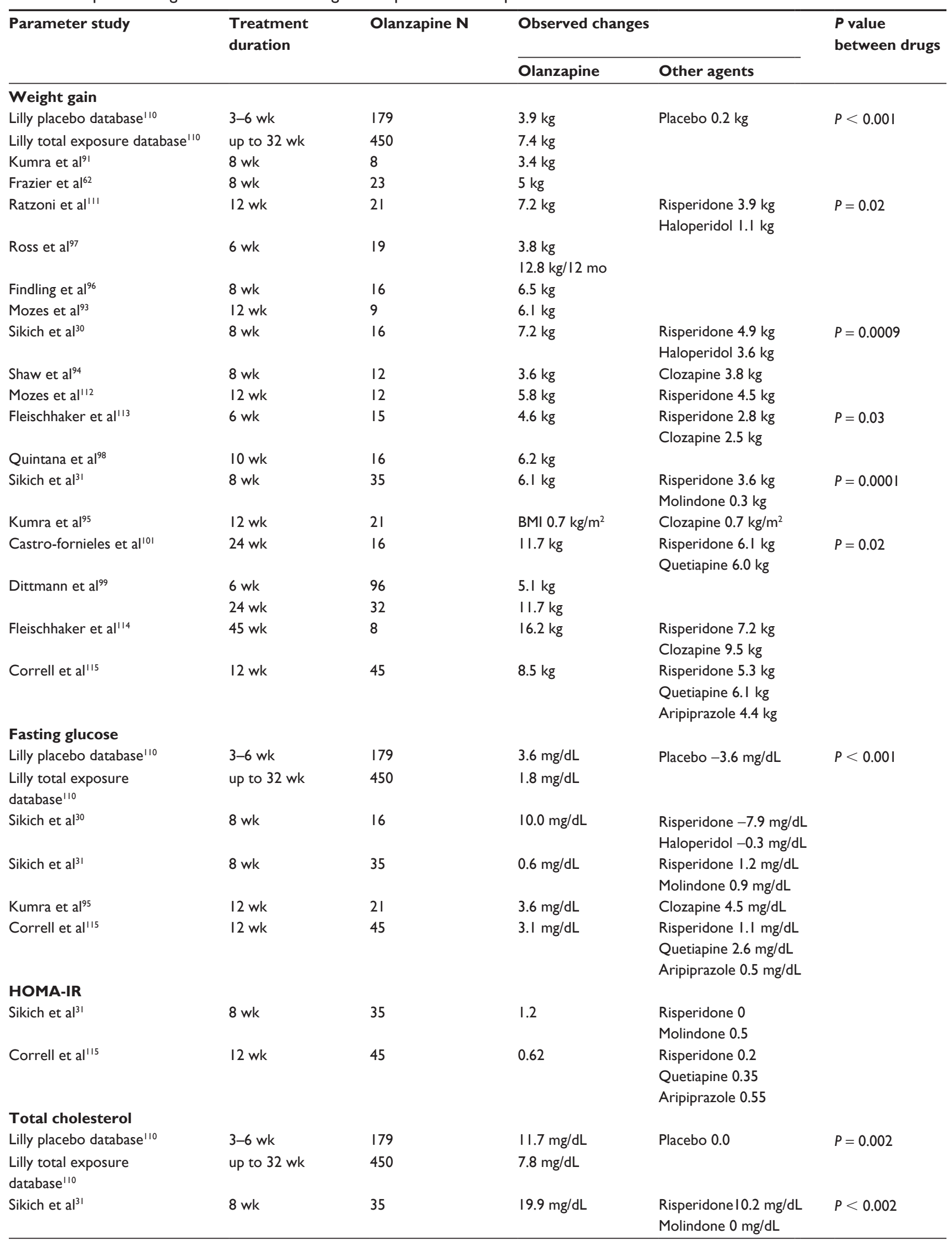


Table 2 (Continued)

\begin{tabular}{|c|c|c|c|c|c|}
\hline \multirow[t]{2}{*}{ Parameter study } & \multirow{2}{*}{$\begin{array}{l}\text { Treatment } \\
\text { duration }\end{array}$} & \multirow[t]{2}{*}{ Olanzapine $\mathbf{N}$} & \multicolumn{2}{|c|}{ Observedchanges } & \multirow{2}{*}{$\begin{array}{l}P \text { value } \\
\text { between drugs }\end{array}$} \\
\hline & & & Olanzapine & Other agents & \\
\hline Kumra et $\mathrm{a}^{95}$ & $12 \mathrm{wk}$ & 21 & $17.2 \mathrm{mg} / \mathrm{dL}$ & & \\
\hline \multirow[t]{3}{*}{ Correll et al $\left.\right|^{115}$} & $12 \mathrm{wk}$ & 45 & $15.6 \mathrm{mg} / \mathrm{dL}$ & Risperidone 3.5 mg/dL & \\
\hline & & & & Quetiapine 9.1 mg/dL & \\
\hline & & & & Aripiprazole $2.8 \mathrm{mg} / \mathrm{dL}$ & \\
\hline \multicolumn{6}{|l|}{ LDL cholesterol } \\
\hline Lilly placebo database ${ }^{110}$ & $3-6 w k$ & 179 & $7.8 \mathrm{mg} / \mathrm{dL}$ & Placebo 0 mg/dL & $P=0.002$ \\
\hline Lilly total exposure database $\mathrm{e}^{110}$ & up to $32 \mathrm{wk}$ & 450 & $7.8 \mathrm{mg} / \mathrm{dL}$ & & \\
\hline \multirow[t]{2}{*}{ Sikich et al ${ }^{30}$} & 8 wk & 16 & $7.6 \mathrm{mg} / \mathrm{dL}$ & Risperidone $2.9 \mathrm{mg} / \mathrm{dL}$ & \\
\hline & & & & Haloperidol $0.1 \mathrm{mg} / \mathrm{dL}$ & \\
\hline \multirow[t]{2}{*}{ Sikich et $\mathrm{a}^{31}$} & $8 w k$ & 35 & $14.7 \mathrm{mg} / \mathrm{dL}$ & Risperidone $-9.6 \mathrm{mg} / \mathrm{dL}$ & $P=0.003$ \\
\hline & & & & Molindone $0.5 \mathrm{mg} / \mathrm{dL}$ & \\
\hline \multirow[t]{3}{*}{ Correll et al ${ }^{115}$} & $12 \mathrm{wk}$ & 45 & $11.5 \mathrm{mg} / \mathrm{dL}$ & Risperidone $0.2 \mathrm{mg} / \mathrm{dL}$ & \\
\hline & & & & Quetiapine $3.9 \mathrm{mg} / \mathrm{dL}$ & \\
\hline & & & & Aripiprazole 7.4 mg/dL & \\
\hline \multicolumn{6}{|l|}{ Triglycerides } \\
\hline Lilly placebo database ${ }^{110}$ & $3-6$ wk & 179 & $26.7 \mathrm{mg} / \mathrm{dL}$ & Placebo $-8.9 \mathrm{mg} / \mathrm{dL}$ & $P=0.007$ \\
\hline Lilly total exposure database $\mathrm{e}^{110}$ & up to $32 \mathrm{wk}$ & 450 & $26.7 \mathrm{mg} / \mathrm{dL}$ & & \\
\hline \multirow[t]{2}{*}{ Sikich et al ${ }^{30}$} & $8 w k$ & 16 & $26 \mathrm{mg} / \mathrm{dL}$ & Risperidone $-2 \mathrm{mg} / \mathrm{dL}$ & \\
\hline & & & & Haloperidol 22 mg/dL & \\
\hline \multirow[t]{2}{*}{ Sikich et al ${ }^{31}$} & $8 w k$ & 35 & $21.6 \mathrm{mg} / \mathrm{dL}$ & Risperidone $7.1 \mathrm{mg} / \mathrm{dL}$ & \\
\hline & & & & Molindone $-5.8 \mathrm{mg} / \mathrm{dL}$ & \\
\hline Kumra et $\mathrm{a}^{95}$ & $12 w k$ & 21 & $11.4 \mathrm{mg} / \mathrm{dL}$ & Clozapine 16.8 mg/dL & \\
\hline \multirow[t]{2}{*}{ Correll et al ${ }^{115}$} & 12 wk & 45 & $24.3 \mathrm{mg} / \mathrm{dL}$ & $\begin{array}{l}\text { Risperidone } 9.7 \mathrm{mg} / \mathrm{dL} \\
\text { Quetiapine } 37.0 \mathrm{mg} / \mathrm{dL}\end{array}$ & \\
\hline & & & & Aripiprazole $-2.4 \mathrm{mg} / \mathrm{dL}$ & \\
\hline
\end{tabular}

studies that included individuals previously exposed to antipsychotics (Table 2). ${ }^{30,31,95}$ Again there is limited information about the long-term course of these lipid changes.

\section{Liver dysfunction}

The Eli Lilly databases also report significant elevations in liver enzymes associated with olanzapine treatment. Alanine aminotransferase (ALT) increased by 20.0 and $21.4 \mathrm{U} / \mathrm{L}$, aspartate aminotransferase (AST) increased by $6.4 \mathrm{U} / \mathrm{L}$ and 8.2 U/L, and $\gamma$-glutamyltransferase (GGT) increased by 7.5 and 9.0 $\mathrm{U} / \mathrm{L}$ in the placebo-controlled and exposure databases, respectively ( $P \leq 0.002$ for each comparison). In contrast, total bilirubin decreased significantly $(-1.7$ and $-1.1 \mu \mathrm{mol} / \mathrm{L})$ in the two databases. Similar increases in ALT and AST have been reported in other pediatric studies of olanzapine. ${ }^{30,31}$ In the TEOSS trial, such elevations were more common in youth treated with olanzapine than those treated with either risperidone or molindone. In this study, there also appeared to be a tendency for these increases to diminish somewhat with continuing treatment. ${ }^{102}$ Eight (1.8\%) of the 454 participants in the Lilly adolescent exposure database discontinued treatment due to liver function problems. These elevations may reflect nonalcoholic steatohepatitis (nonalcoholic fatty liver disease), although imaging studies and long-term follow-up is not yet available. In a retrospective chart review of youth treated with olanzapine alone, divalproex alone, or the combination of olanzapine and divalproex, 59\% of those treated with olanzapine alone had at least 1 elevated hepatic enzyme over an average of 8 months of treatment while only $26 \%$ of those treated with divalproex alone did. However, all of those treated with the combination experienced at least 1 elevation and $42 \%$ of these had persistent elevations throughout the treatment period. One of the youth treated with both agents developed clinically significant steatohepatitis that resolved when the olanzapine was stopped. ${ }^{121}$

\section{Hyperprolactinemia}

In adults, olanzapine has not been associated with significant increases in prolactin. However, children and adolescents appear very sensitive to the prolactin-increasing effects of all antipsychotics, including olanzapine. ${ }^{122}$ The Eli Lilly placebo databases report acute prolactin increases of $11.4 \mu \mathrm{g} / \mathrm{L}$ with olanzapine compared with a slight decrease with placebo $(P<0.001)$. In the longer-term exposure database, the increase is much more significant at $23.0 \mu \mathrm{g} / \mathrm{L}$ compared with a decrease of $-4.2 \mu \mathrm{g} / \mathrm{L}$ in the pooled adult 
data $(P=0.004)$. Interestingly, fewer female adolescents experienced prolactin elevations than male adolescents. Similar changes have been described in other clinical trials..$^{30,31}$ Further, Wudarsky reported that 7 of 10 youth treated with olanzapine had elevations above the upper limits of normal for their age and gender. However, prolactin elevations with risperidone have consistently been found to be more extreme than with olanzapine in pediatric patients. ${ }^{30,31}$ It appears that olanzapine plasma concentration is significantly correlated with serum prolactin levels. ${ }^{123}$ However, most clinical trials do not report high rates of prolactin-related adverse events, such as menstrual irregularities, gynecomastia, or galactorrhea. The large Eli Lilly exposure database identified such problems in only $0.6 \%-4.2 \%$ of participants. The long-term consequences of moderate elevations in prolactin during adolescence are unknown.

\section{Sedation}

Most pediatric trials of olanzapine report high rates of sedation ranging from about $40 \%$ to $91 \%{ }^{30,31,95,96,100}$ In the Eli Lilly databases, the incidence appears somewhat lower (17.4\%-19.0\%). However, if the reported rates of somnolence are generally additive to those of sedation, the rates move into the $40 \%$ range reported in other studies. Unfortunately, sedation often does not resolve in individuals who continue long-term treatment. ${ }^{100,102}$ Sedation can have significant impact upon a youth's ability to participate in school and other age-appropriate activities. Less than 1\% of youth in Eli Lilly's databases discontinued participation due to sedation.

\section{Extrapyramidal symptoms}

Almost all types of extrapyramidal adverse effects, including parkinsonian symptoms, dystonia, dyskinesia, tardive dyskinesia, akathisia, and neuroleptic malignant syndrome (NMS), have been reported in youth treated with olanzapine. However, these adverse events appear to occur much less often with olanzapine than with other antipsychotics including aripiprazole in youth. The incidence in the Lilly exposure database was $2.3 \%$ for parkinsonian symptoms, $5.5 \%$ for akathisia, and $1.4 \%$ for dyskinetic movements. Generally, those symptoms that do occur are minimal to mild. In comparative studies, olanzapine is consistently associated with fewer and less-severe extrapyramidal adverse events than risperidone, haloperidol, or molindone. ${ }^{30,31,100}$ There is 1 case report of persistent dystonic movements emerging during olanzapine treatment and persisting up to 6 weeks after switching to clozapine treatment. ${ }^{124}$ However, very few children and adolescents have been maintained for an extended period on a single antipsychotic or followed for sufficiently long periods to rigorously assess the medication-specific incidence of this late appearing and persistent adverse effect.

\section{Neuroleptic malignant syndrome}

NMS is a rare, potentially fatal, and idiosyncratic drug reaction that often occurs early in the course of antipsychotic treatment. NMS previously has been associated with the use of classical high-potency neuroleptics. ${ }^{125,126}$ Case reports suggest that NMS resulting from treatment with olanzapine and other SGAs has a more insidious course than NMS precipitated by first-generation high-potency agents. In addition, temperature elevations may emerge late in the course. Cognitive symptoms including agitation and delirium may be more prominent. However, there have been two case reports of classic NMS occurring during olanzapine monotherapy, ${ }^{127,128}$ one with olanzapine overdose, ${ }^{129}$ and several in the context of polypharmacy with other psychotropics (as described in two recent reviews). ${ }^{126,130}$

\section{Hematologic effects}

Although clozapine is best known for its risk of hematologic abnormalities, there are many case reports of neutropenia being caused by other antipsychotics as well. Olanzapine and ziprasidone seem to be more likely than the other newer antipsychotics to cause such abnormalities. ${ }^{131}$ There are some case reports where olanzapine was the only medication being taken. ${ }^{132}$ Consequently, the FDA required a label change noting the risk of neutropenia and leukopenia with olanzapine treatment in August 2009. The label notes that this risk appears to be heightened in individuals with a history of blood dyscrasias or low white blood cell counts, particularly those induced by other drugs or those on drugs that have similar effects. In such cases, the patient's blood count should be monitored frequently when treatment is initiated and treatment should be interrupted if the absolute neutrophil count drops below 1000 cells $/ \mathrm{cm}^{3}$. It is unknown whether the risk for neutropenia is greater in the pediatric population than in the adult population.

\section{Overdose}

In adult studies, Lily data of over 3,100 subjects showed that the largest ingestion was $300 \mathrm{mg}$ and that person did well with supportive care. However, there are multiple other reports of fatalities that some believe are related to olanzapine. ${ }^{133-135}$ There have been at least two fatalities in children who have overdosed on olanzapine. ${ }^{136}$ Often, individuals 


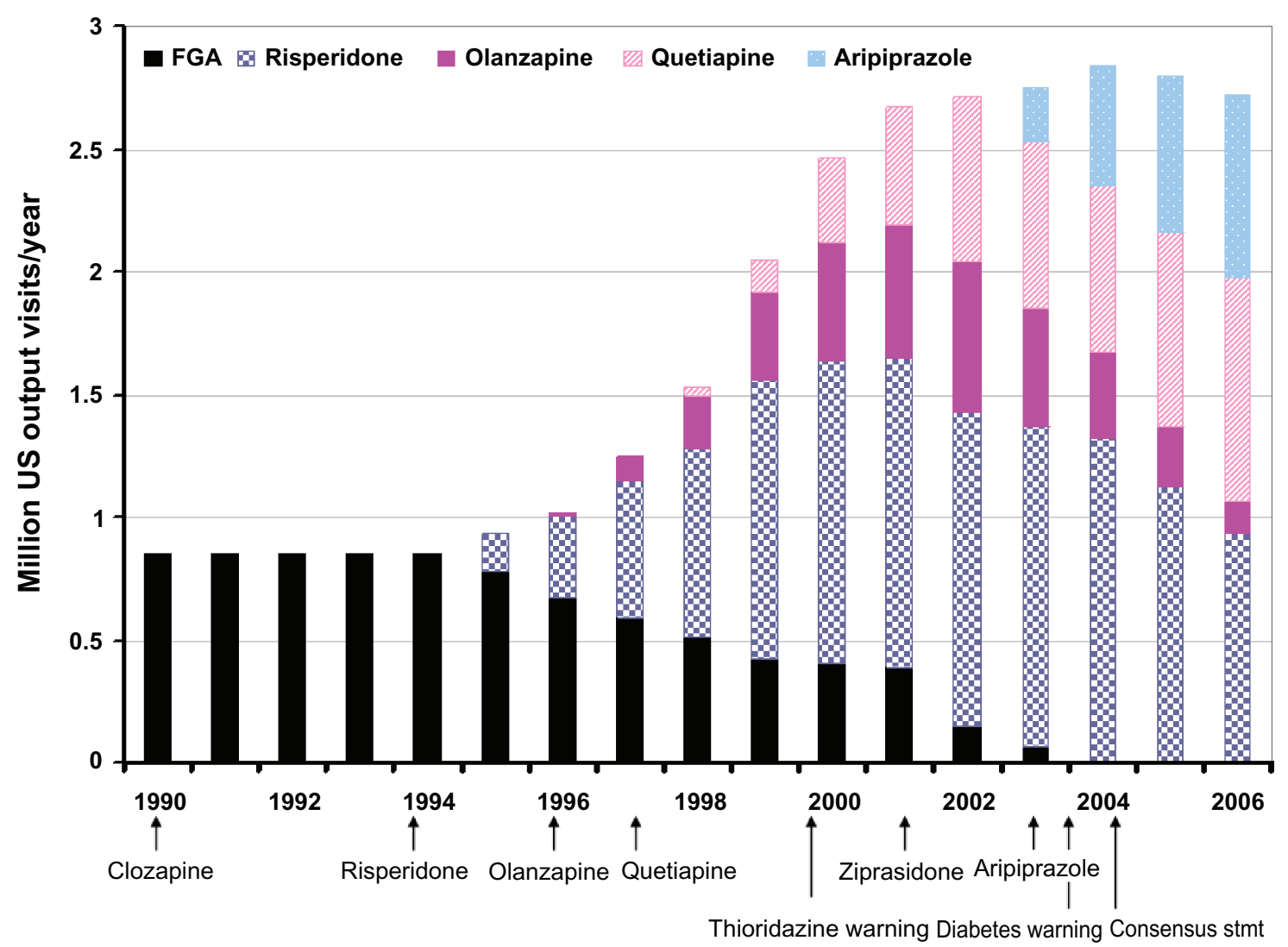

Figure 2 Patterns of antipsychotic use in the pediatric population of the United States. Following the introduction of each second-generation antipsychotic except clozapine, there has been rapid use within the pediatric population. However, risperidone, the first agent introduced after clozapine, has consistently been used more widely than the other agents. Further, safety considerations appear to have limited use of clozapine, ziprasidone, and earlier in 2003, olanzapine. This figure is a synthesis of data from multiple sources. ${ }^{135-140,142}$ Number of prescriptions and proportion related to each agent are approximate.

with olanzapine overdoses develop EPS or NMS, respiratory symptoms, and mental status changes. ${ }^{129,137-139}$ Overdoses in pediatric patients are reviewed by Theisen. ${ }^{140}$ Management is primarily supportive and symptoms may take several days to a few weeks to fully resolve.

\section{Olanzapine use in the pediatric population}

The pattern of olanzapine's use over time in the US pediatric population relative to other antipsychotics is shown in Figure 2. When olanzapine was approved by the FDA in 1996, it almost immediately began being used in the pediatric population. ${ }^{140-149}$ However, its use never became as prevalent as risperidone's. Quetiapine's use was of similar magnitude by 2001. However, as data about olanzapine-associated weight gain emerged, the FDA issued requirements that SGA labels warn about the weight and metabolic risks; the American Diabetes Association and the American Psychiatric Association released a consensus statement indicating that olanzapine and clozapine had the greatest risk for such side effects and olanzapine use in the pediatric population quickly diminished to $5 \%$ or less of the total antipsychotics prescribed. ${ }^{146,148}$

Evidence from the CATIE trial that showed a slight advantage of olanzapine over other first-line antipsychotics in total duration of treatment and symptom response and from a first-episode study showing neuroimaging benefits compared with haloperidol, as well as the similarities between the binding profiles of olanzapine and clozapine, led some clinicians to use olanzapine in a few youth with very severe or persistent psychotic symptoms..$^{27,29,150}$ Youth with bipolar disorder are even less likely to be treated with olanzapine. In a recent study of pediatric bipolar treatment, it was used less often than any other antipsychotic (including FGAs). ${ }^{151}$

Olanzapine appears to be used more frequently in some parts of Europe but still to a lesser extent than either risperidone or quetiapine. In the CAFEPS longitudinal naturalistic study of youth with positive psychotic symptoms about $15 \%$ were treated with olanzapine. ${ }^{101}$ In Canada, use is also somewhat greater than in the United States with about 6000 children ( $\sim 22 \%$ of those who are treated with antipsychotics) receiving prescriptions for olanzapine annually between 
2003 and 2006. ${ }^{147}$ In countries outside the United States, aripiprazole appears to be less frequently used, so olanzapine and quetiapine are likely to be viewed as the antipsychotics with the least risk for EPS.

\section{Conclusions}

Olanzapine has clear efficacy for pedBP and EOSS. However, it also appears to have very great potential for promoting weight gain, increased insulin secretion, and dyslipidemia in children and adolescents. These adverse risks appear to be remarkably increased relative to other antipsychotics with the possible exception of clozapine. In the light of this extreme risk and because there is no compelling evidence that olanzapine has greater antipsychotic efficacy than other agents in either unselected youth with EOSS and other psychotic illnesses or in treatment-resistant EOSS, we argue that olanzapine should not be considered a first-line treatment for EOSS. Because there is clear evidence that clozapine has superior efficacy to olanzapine in treatment-resistant EOSS, we feel clinicians and families should seriously consider a trial of clozapine rather than olanzapine in such youth. There are no comparative studies examining the mood-stabilizing or antimanic properties of olanzapine relative to other SGAs. In the absence of any empiric data regarding comparative efficacy, olanzapine's heightened risks for weight gain and metabolic dysregulation suggest to the authors that it should not be considered a first-line treatment for pedBP either. However, because there is no treatment of choice for youth with pedBP, who have failed to respond to multiple first-line treatments, olanzapine might have a role in treating such children and adolescents.

Although olanzapine is unlikely to be used frequently in the pediatric population, it remains an alternative for some individuals. Such individuals might include those who are underweight, have no family history of diabetes or dyslipidemia, or are particularly sensitive to the extrapyramidal side effects of antipsychotics with more potent dopamine $\mathrm{D}_{2}$ receptor binding. These conclusions are supported by the FDA's recent decision to approve olanzapine for the treatment of adolescents with schizophrenia or manic/mixed states in bipolar disorder, provided clinicians and families carefully consider prescribing other agents first due to olanzapine's marked risks for significant weight gain and lipid dysregulation in adolescents.

Olanzapine has played a critical role in alerting scientists and the public to the metabolic consequences of most antipsychotics, particularly within children and adolescents. The consistent weight and metabolic changes observed in olanzapine-treated youth spurred investigations of such effects among youth treated with other antipsychotics and provided a strong impetus for long-term studies of antipsychotic tolerability in youth.

\section{Disclosures}

Dr Maloney has received software for a computer intervention in schizophrenia from Posit Science. Dr Sikich receives research funding from NIMH, NIH, Foundation of Hope, Case Western Reserve University (subcontract from NICHD), NY Institute for Mental Hygiene Research (subcontract from NIMH), and Bristol Myers-Squibb. She is participating or has participated in clinical trials with Otsuka, Bristol MyersSquibb, Neuropharm, Curemark, and Seaside Pharmaceuticals. She also received medication for clinical trials from Eli Lilly, Janssen, and Bristol Myers-Squibb, and software for a computer intervention in schizophrenia from Posit Science. She has served as a consultant for Sanofi Aventis within the past 2 years. She has given CME talks that have been indirectly supported by Bristol Myers-Squibb.

\section{References}

1. Hafner H, Nowotny B. Epidemiology of early-onset schizophrenia. Eur Arch Psychiatry Clin Neurosci. 1995;245:80-92.

2. Maziade M, Gingras N, Rodrigue C, et al. Long-term stability of diagnosis and symptom dimensions in a systematic sample of patients with onset of schizophrenia in childhood and early adolescence. I: nosology, sex and age of onset. Br J Psychiatry. 1996;169(3):361-370.

3. Thomsen PH. Schizophrenia with childhood and adolescent onset $-\mathrm{a}$ nationwide register-based study. Acta Psychiatr Scand. 1996;94(3): 187-193.

4. Schimmelmann BG, Conus P, Cotton S, McGorry PD, Lambert M. Pretreatment, baseline, and outcome differences between early-onset and adult-onset psychosis in an epidemiological cohort of 636 first-episode patients. Schizophr Res. 2007;95(1-3):1-8.

5. Luoma S, Hakko H, Ollinen T, Jarvelin MR, Lindeman S. Association between age at onset and clinical features of schizophrenia: the Northern Finland 1966 birth cohort study. Eur Psychiatry. 2008;23(5):331-335.

6. Hafner H, Riecher A, Maurer K, Loffler W, Munk-Jorgensen P, Stromgren E. How does gender influence age at first hospitalization for schizophrenia? A transnational case register study. Psychol Med. 1989;19(4): 903-918.

7. Remschmidt HE, Schulz E, Martin M, Warnke A, Trott GE. Childhoodonset schizophrenia: history of the concept and recent studies. Schizophr Bull. 1994;20(4):727-745.

8. Russell AT. The clinical presentation of childhood-onset schizophrenia. Schizophr Bull. 1994;20(4):631-646.

9. Spencer EK, Campbell M. Children with schizophrenia: diagnosis, phenomenology, and pharmacotherapy. Schizophr Bull. 1994;20(4):713-725.

10. Werry JS, McClellan JM, Andrews LK, Ham M. Clinical features and outcome of child and adolescent schizophrenia. Schizophr Bull. 1994;20(4):619-630.

11. Schaeffer JL, Ross RG. Childhood-onset schizophrenia: premorbid and prodromal diagnostic and treatment histories. J Am Acad Child Adolesc Psychiatry. 2002;41(5):538-545.

12. Eggers C, Bunk D. The long-term course of childhood-onset schizophrenia: a 42-year followup. Schizophr Bull. 1997;23:105-117.

13. Ropcke B, Eggers C. Early-onset schizophrenia: a 15-year follow-up. Eur Child Adolesc Psychiatry. 2005;14(6):341-350. 
14. Basso MR, Nasrallah HA, Olson SC, Bornstein RA. Cognitive deficits distinguish patients with adolescent- and adult- onset schizophrenia Neuropsychiatry Neuropsychol Behav Neurol. 1997;10(2):107-112.

15. Giedd JN, Jeffries NO, Blumenthal J, et al. Childhood-onset schizophrenia: progressive brain changes during adolescence. Biol Psychiatry. 1999;46(7):892-898.

16. Tuulio-Henriksson A, Partonen T, Suvisaari J, Haukka J, Lonnqvist J. Age at onset and cognitive functioning in schizophrenia. Br J Psychiatry. 2004;185:215-219.

17. Biswas P, Malhotra S, Malhotra A, Gupta N. Comparative study of neuropsychological correlates in schizophrenia with onset in childhood, adolescence and adulthood. Eur Child Adolesc Psychiatry. 2006;15(6):360-366.

18. Frazier JA, McClellan J, Findling RL, et al. Treatment of early-onset schizophrenia spectrum disorders (TEOSS): demographic and clinical characteristics. J Am Acad Child Adolesc Psychiatry. 2007;46(8): 979-988.

19. Jarbin H, Ott Y, Von Knorring AL. Adult outcome of social function in adolescent-onset schizophrenia and affective psychosis. J Am Acad Child Adolesc Psychiatry. 2003;42(2):176-183.

20. Fleischhaker C, Schulz E, Tepper K, Martin M, Hennighausen K, Remschmidt H. Long-term course of adolescent schizophrenia. Schizophr Bull. 2005;31(3):769-780.

21. Remschmidt H, Martin M, Fleischhaker C, et al. Forty-two-years later: the outcome of childhood-onset schizophrenia. J Neural Transm. 2007;114(4):505-512.

22. Sikich L. Individual and school-based interventions. In: Findling R, Schluz S, editors. Schizophrenia in Adolescents and Children: Assessment, Neurobiology and Treatment. Baltimore (MD): John Hopkins University Press; 2005:257-287.

23. Pool D, Bloom W, Mielke DH, Roniger JJ Jr, Gallant DM. A controlled evaluation of loxitane in seventy-five adolescent schizophrenic patients. Curr Ther Res Clin Exp. 1976;19(1):99-104.

24. Realmuto GM, Erickson WD, Yellin AM, Hopwood JH, Greenberg LM. Clinical comparison of thiothixene and thioridazine in schizophrenic adolescents. Am J Psychiatry. 1984;141:440-442.

25. Keepers GA, Clappison VJ, Casey DE. Initial anticholinergic prophylaxis for neuroleptic-induced extrapyramidal syndromes. Arch Gen Psychiatry. 1983;40(10):1113-1117.

26. Kumra S, Frazier JA, Jacobsen LK, et al. Childhood-onset schizophrenia. A double-blind clozapine-haloperidol comparison. Arch Gen Psychiatry. 1996;53(12):1090-1097.

27. Lieberman JA, Tollefson G, Tohen M, et al. Comparative efficacy and safety of atypical and conventional antipsychotic drugs in first-episode psychosis: a randomized, double-blind trial of olanzapine versus haloperidol. Am J Psychiatry. 2003;160(8):1396-1404.

28. Green AI, Lieberman JA, Hamer RM, et al. Olanzapine and haloperidol in first episode psychosis: two-year data. Schizophr Res. 2006;86(1-3): $234-243$.

29. Lieberman JA, Stroup TS, McEvoy JP, et al. Effectiveness of antipsychotic drugs in patients with chronic schizophrenia. $N$ Engl J Med. 2005;353(12):1209-1223.

30. Sikich L, Hamer RM, Bashford RA, Sheitman BB, Lieberman JA. A pilot study of risperidone, olanzapine, and haloperidol in psychotic youth: a double-blind, randomized, 8-week trial. Neuropsychopharmacology. 2004;29(1):133-145.

31. Sikich L, Frazier JA, McClellan J, et al. Double-blind comparison of first- and second-generation antipsychotics in early-onset schizophrenia and schizo-affective disorder: findings from the treatment of early-onset schizophrenia spectrum disorders (TEOSS) study. Am J Psychiatry. 2008;165(11):1420-1431.

32. Beesdo K, Hofler M, Leibenluft E, Lieb R, Bauer M, Pfennig A. Mood episodes and mood disorders: patterns of incidence and conversion in the first three decades of life. Bipolar Disord. 2009;11(6):637-649.

33. Merikangas KR, Akiskal HS, Angst J, et al. Lifetime and 12-month prevalence of bipolar spectrum disorder in the National Comorbidity Survey replication. Arch Gen Psychiatry. 2007;64(5):543-552.
34. Perlis RH, Dennehy EB, Miklowitz DJ, et al. Retrospective age at onset of bipolar disorder and outcome during two-year follow-up: results from the STEP-BD study. Bipolar Disord. 2009;11(4):391-400.

35. Oedegaard KJ, Syrstad VE, Morken G, Akiskal HS, Fasmer OB. A study of age at onset and affective temperaments in a Norwegian sample of patients with mood disorders. J Affect Disord. 2009;118(1-3):229-233.

36. Moreno C, Laje G, Blanco C, Jiang H, Schmidt AB, Olfson M. National trends in the outpatient diagnosis and treatment of bipolar disorder in youth. Arch Gen Psychiatry. 2007;64(9):1032-1039.

37. Youngstrom EA, Birmaher B, Findling RL. Pediatric bipolar disorder: validity, phenomenology, and recommendations for diagnosis. Bipolar Disord. 2008;10(1 Pt 2):194-214.

38. Geller B, Tillman R, Bolhofner K. Proposed definitions of bipolar I disorder episodes and daily rapid cycling phenomena in preschoolers, school-aged children, adolescents, and adults. J Child Adolesc Psychopharmacol. 2007;17(2):217-222.

39. Tillman R, Geller B. Definitions of rapid, ultrarapid, and ultradian cycling and of episode duration in pediatric and adult bipolar disorders: a proposal to distinguish episodes from cycles. J Child Adolesc Psychopharmacol. 2003;13(3):267-271.

40. Birmaher B, Axelson D, Strober M, et al. Comparison of manic and depressive symptoms between children and adolescents with bipolar spectrum disorders. Bipolar Disord. 2009;11(1):52-62.

41. Leibenluft E, Charney DS, Towbin KE, Bhangoo RK, Pine DS. Defining clinical phenotypes of juvenile mania. Am J Psychiatry. 2003;160(3):430-437.

42. Geller B, Tillman R, Craney JL, Bolhofner K. Four-year prospective outcome and natural history of mania in children with a prepubertal and early adolescent bipolar disorder phenotype. Arch Gen Psychiatry. 2004;61(5):459-467.

43. Birmaher B, Axelson D. Course and outcome of bipolar spectrum disorder in children and adolescents: a review of the existing literature. Dev Psychopathol. 2006;18(4):1023-1035.

44. Rende R, Birmaher B, Axelson D, et al. Psychotic symptoms in pediatric bipolar disorder and family history of psychiatric illness. $J$ Affect Disord. 2006;96(1-2):127-131.

45. Strober M, Birmaher B, Ryan N, et al. Pediatric bipolar disease: current and future perspectives for study of its long-term course and treatment. Bipolar Disord. 2006;8(4):311-321.

46. DelBello MP, Hanseman D, Adler CM, Fleck DE, Strakowski SM. Twelve-month outcome of adolescents with bipolar disorder following first hospitalization for a manic or mixed episode. Am J Psychiatry. 2007; 164(4):582-590.

47. Lewinsohn P, Seeley J, Klein D. Bipolar disorder in adolescents: epidemiology and suicidal behavior. In: Geller B, DelBello MP, editors. Bipolar Disorder in Childhood and Early Adolescence. New York: Guilford; 2003:7-24.

48. Axelson D, Birmaher B, Strober M, et al. Phenomenology of children and adolescents with bipolar spectrum disorders. Arch Gen Psychiatry. 2006;63(10):1139-1148.

49. Caetano SC, Olvera RL, Hunter K, et al. Association of psychosis with suicidality in pediatric bipolar I, II and bipolar NOS patients. J Affect Disord. 2006;91(1):33-37.

50. Geller B, Cooper TB, Sun K, et al. Double-blind and placebocontrolled study of lithium for adolescent bipolar disorders with secondary substance dependency. J Am Acad Child Adolesc Psychiatry. 1998;37(2):171-178.

51. Kafantaris V, Coletti DJ, Dicker R, Padula G, Kane JM. Lithium treatment of acute mania in adolescents: a large open trial. J Am Acad Child Adolesc Psychiatry. 2003;42(9):1038-1045.

52. Kafantaris V, Coletti DJ, Dicker R, Padula G, Pleak RR, Alvir JM. Lithium treatment of acute mania in adolescents: a placebo-controlled discontinuation study. J Am Acad Child Adolesc Psychiatry. 2004;43(8):984-993.

53. Kafantaris V, Coletti DJ, Dicker R, Padula G, Kane JM. Adjunctive antipsychotic treatment of adolescents with bipolar psychosis. J Am Acad Child Adolesc Psychiatry. 2001;40(12):1448-1456. 
54. Wagner KD, Weller EB, Carlson GA, et al. An open-label trial of divalproex in children and adolescents with bipolar disorder. $J$ Am Acad Child Adolesc Psychiatry. 2002;41(10):1224-1230.

55. Pavuluri MN, Henry DB, Carbray JA, Naylor MW, Janicak PG. Divalproex sodium for pediatric mixed mania: a 6-month prospective trial. Bipolar Disord. 2005;7(3):266-273.

56. Kowatch RA, Suppes T, Carmody TJ, et al. Effect size of lithium, divalproex sodium, and carbamazepine in children and adolescents with bipolar disorder. J Am Acad Child Adolesc Psychiatry. 2000;39(6): 713-720.

57. Findling RL, McNamara NK, Gracious BL, et al. Combination lithium and divalproex sodium in pediatric bipolarity. $\mathrm{J} \mathrm{Am} \mathrm{Acad} \mathrm{Child} \mathrm{Adolesc}$ Psychiatry. 2003;42(8):895-901.

58. Wagner KD, Kowatch RA, Emslie GJ, et al. A double-blind, randomized, placebo-controlled trial of oxcarbazepine in the treatment of bipolar disorder in children and adolescents. Am J Psychiatry. 2006;163(7): 1179-1186.

59. Wagner KD, Redden L, Kowatch RA, et al. A double-blind, randomized, placebo-controlled trial of divalproex extended-release in the treatment of bipolar disorder in children and adolescents. J Am Acad Child Adolesc Psychiatry. 2009;48(5):519-532.

60. Pavuluri MN, Henry DB, Carbray JA, Sampson G, Naylor MW, Janicak PG. Open-label prospective trial of risperidone in combination with lithium or divalproex sodium in pediatric mania. J Affect Disord. 2004;82 Suppl 1:S103-S111.

61. Delbello MP, Schwiers ML, Rosenberg HL, Strakowski SM. A doubleblind, randomized, placebo-controlled study of quetiapine as adjunctive treatment for adolescent mania. J Am Acad Child Adolesc Psychiatry. 2002;41(10):1216-1223.

62. Frazier JA, Biederman J, Tohen M, et al. A prospective open-label treatment trial of olanzapine monotherapy in children and adolescents with bipolar disorder. J Child Adolesc Psychopharmacol. 2001;11(3):239-250.

63. Barzman DH, DelBello MP, Adler CM, Stanford KE, Strakowski SM. The efficacy and tolerability of quetiapine versus divalproex for the treatment of impulsivity and reactive aggression in adolescents with co-occurring bipolar disorder and disruptive behavior disorder(s). J Child Adolesc Psychopharmacol. 2006;16(6):665-670.

64. Tohen M, Kryzhanovskaya L, Carlson G, et al. Olanzapine versus placebo in the treatment of adolescents with bipolar mania. Am J Psychiatry. 2007;164(10):1547-1556.

65. Findling RL, Nyilas M, Forbes RA, et al. Acute treatment of pediatric bipolar I disorder, manic or mixed episode, with aripiprazole: a randomized, double-blind, placebo-controlled study. J Clin Psychiatry. 2009; 70(10):1441-1451.

66. Haas M, Delbello MP, Pandina G, et al. Risperidone for the treatment of acute mania in children and adolescents with bipolar disorder: a randomized, double-blind, placebo-controlled study. Bipolar Disord. 2009;11(7):687-700.

67. FDA_website. fda.gov/downloads/Drugs/DevelopmentApprovalProces s?DevelopmentResources/UCM163241.pdf. Published 2007. Accessed Sep 15, 2009.

68. Young RC, Biggs JT, Ziegler VE, Meyer DA. A rating scale for mania: reliability, validity and sensitivity. Br J Psychiatry. 1978;133: 429-435.

69. DelBello MP, Chang K, Welge JA, et al. A double-blind, placebocontrolled pilot study of quetiapine for depressed adolescents with bipolar disorder. Bipolar Disord. 2009;11(5):483-493.

70. Bymaster FP, Calligaro DO, Falcone JF, et al. Radioreceptor binding profile of the atypical antipsychotic olanzapine. Neuropsychopharmacology. 1996;14(2):87-96.

71. Fumagalli F, Frasca A, Sparta M, Drago F, Racagni G, Riva MA. Longterm exposure to the atypical antipsychotic olanzapine differently upregulates extracellular signal-regulated kinases 1 and 2 phosphorylation in subcellular compartments of rat prefrontal cortex. Mol Pharmacol. 2006;69(4):1366-1372.

72. Wirshing DA, Wirshing WC, Kysar L, etal. Novel antipsychotics: comparison of weight gain liabilities. J Clin Psychiatry. 1999;60(6):358-363.
73. Kroeze WK, Hufeisen SJ, Popadak BA, et al. H1-histamine receptor affinity predicts short-term weight gain for typical and atypical antipsychotic drugs. Neuropsychopharmacology. 2003;28(3): 519-526.

74. Templeman LA, Reynolds GP, Arranz B, San L. Polymorphisms of the 5-HT2C receptor and leptin genes are associated with antipsychotic drug-induced weight gain in Caucasian subjects with a first-episode psychosis. Pharmacogenet Genomics. 2005;15(4):195-200.

75. Ujike H, Nomura A, Morita Y, et al. Multiple genetic factors in olanzapine-induced weight gain in schizophrenia patients: a cohort study. J Clin Psychiatry. 2008;69(9):1416-1422.

76. Gunes A, Melkersson KI, Scordo MG, Dahl ML. Association between HTR2C and HTR2A polymorphisms and metabolic abnormalities in patients treated with olanzapine or clozapine. J Clin Psychopharmacol. 2009;29(1):65-68.

77. Kassahun K, Mattiuz E, Nyhart E Jr, et al. Disposition and biotransformation of the antipsychotic agent olanzapine in humans. Drug Metab Dispos. 1997;25(1):81-93.

78. Kando JC, Shepski JC, Satterlee W, Patel JK, Reams SG, Green AI. Olanzapine: a new antipsychotic agent with efficacy in the management of schizophrenia. Ann Pharmacother. 1997;31(11):1325-1334.

79. Lucas RA, Gilfillan DJ, Bergstrom RF. A pharmacokinetic interaction between carbamazepine and olanzapine: observations on possible mechanism. Eur J Clin Pharmacol. 1998;54(8):639-643.

80. Callaghan JT, Bergstrom RF, Ptak LR, Beasley CM. Olanzapine. Pharmacokinetic and pharmacodynamic profile. Clin Pharmacokinet. 1999;37(3):177-193.

81. Kelly DL, Conley RR, Tamminga CA. Differential olanzapine plasma concentrations by sex in a fixed-dose study. Schizophr Res. 1999;40(2):101-104.

82. Hiemke C, Peled A, Jabarin M, et al. Fluvoxamine augmentation of olanzapine in chronic schizophrenia: pharmacokinetic interactions and clinical effects. J Clin Psychopharmacol. 2002;22(5):502-506.

83. Kroon LA. Drug interactions with smoking. Am J Health Syst Pharm. 2007;64(18):1917-1921.

84. Spina E, de Leon J. Metabolic drug interactions with newer antipsychotics: a comparative review. Basic Clin Pharmacol Toxicol. 2007;100(1):4-22.

85. Darby JK, Pasta DJ, Wilson MG, Herbert J. Long-term therapeutic drug monitoring of risperidone and olanzapine identifies altered steady-state pharmacokinetics: a clinical, two-group, naturalistic study. Clin Drug Investig. 2008;28(9):553-564.

86. Markowitz JS, DeVane CL, Malcolm RJ, et al. Pharmacokinetics of olanzapine after single-dose oral administration of standard tablet versus normal and sublingual administration of an orally disintegrating tablet in normal volunteers. J Clin Pharmacol. 2006;46(2):164-171.

87. Grothe DR, Calis KA, Jacobsen L, et al. Olanzapine pharmacokinetics in pediatric and adolescent inpatients with childhood-onset schizophrenia. J Clin Psychopharmacol. 2000;20(2):220-225.

88. Theisen FM, Haberhausen M, Schulz E, et al. Serum levels of olanzapine and its $\mathrm{N}$-desmethyl and 2-hydroxymethyl metabolites in child and adolescent psychiatric disorders: effects of dose, diagnosis, age, sex, smoking, and comedication. Ther Drug Monit. 2006;28(6): 750-759.

89. Bachmann CJ, Haberhausen M, Heinzel-Gutenbrunner M, Remschmidt H, Theisen FM. Large intraindividual variability of olanzapine serum concentrations in adolescent patients. Ther Drug Monit. 2008;30(1):108-112.

90. Aichhorn W, Marksteiner J, Walch T, et al. Age and gender effects on olanzapine and risperidone plasma concentrations in children and adolescents. J Child Adolesc Psychopharmacol. 2007;17(5):665-674.

91. Kumra S, Jacobsen LK, Lenane M, et al. Childhood-onset schizophrenia: an open-label study of olanzapine in adolescents. $J$ Am Acad Child Adolesc Psychiatry. 1998;37(4):377-385.

92. Sholevar EH, Baron DA, Hardie TL. Treatment of childhood-onset schizophrenia with olanzapine. J Child Adolesc Psychopharmacol. 2000;10(2):69-78. 
93. Mozes T, Greenberg Y, Spivak B, Tyano S, Weizman A, Mester R. Olanzapine treatment in chronic drug-resistant childhood-onset schizophrenia: an open-label study. J Child Adolesc Psychopharmacol. 2003;13(3):311-317.

94. Shaw P, Sporn A, Gogtay N, et al. Childhood-onset schizophrenia: A double-blind, randomized clozapine-olanzapine comparison. Arch Gen Psychiatry. 2006;63(7):721-730.

95. Kumra S, Kranzler H, Gerbino-Rosen G, et al. Clozapine and "high-dose" olanzapine in refractory early-onset schizophrenia: a 12-week randomized and double-blind comparison. Biol Psychiatry. 2008;63(5):524-529.

96. Findling RL, McNamara NK, Youngstrom EA, Branicky LA, Demeter CA, Schulz SC. A prospective, open-label trial of olanzapine in adolescents with schizophrenia. J Am Acad Child Adolesc Psychiatry. 2003;42(2):170-175.

97. Ross RG, Novins D, Farley GK, Adler LE. A 1-year open-label trial of olanzapine in school-age children with schizophrenia. J Child Adolesc Psychopharmacol. 2003;13(3):301-309.

98. Quintana H, Wilson MS 2nd, Purnell W, Layman AK, Mercante D. An open-label study of olanzapine in children and adolescents with schizophrenia. $J$ Psychiatr Pract. 2007;13(2):86-96.

99. Dittmann RW, Meyer E, Freisleder FJ, et al. Effectiveness and tolerability of olanzapine in the treatment of adolescents with schizophrenia and related psychotic disorders: results from a large, prospective, open-label study. J Child Adolesc Psychopharmacol. 2008;18(1): 54-69.

100. Gothelf D, Apter A, Reidman J, et al. Olanzapine, risperidone and haloperidol in the treatment of adolescent patients with schizophrenia. J Neural Transm. 2003;110(5):545-560.

101. Castro-Fornieles J, Parellada M, Soutullo CA, et al. Antipsychotic treatment in child and adolescent first-episode psychosis: a longitudinal naturalistic approach. J Child Adolesc Psychopharmacol. 2008;18(4): 327-336.

102. Findling R, Johnson J, McClellan J, et al. Double-blind maintenance safety and effectiveness findings from the Treatment of Early-Onset Schizophrenia Spectrum Study (TEOSS). J Am Acad Child Adolesc Psychiatry.2010;49(6):583-594.

103. Kryzhanovskaya L, Schulz SC, McDougle C, et al. Olanzapine versus placebo in adolescents with schizophrenia: a 6-week, randomized, double-blind, placebo-controlled trial. J Am Acad Child Adolesc Psychiatry. 2009;48(1):60-70.

104. Overall JE, Pfefferbaum B. The Brief Psychiatric Rating Scale for Children. Psychopharmacol Bull. 1982;18(2):10-16.1978;133:429-435.

105. Hughes CW, Rintelmann J, Emslie GJ, Lopez M, MacCabe N. A revised anchored version of the BPRS-C for childhood psychiatric disorders. J Child Adolesc Psychopharmacol. Spring 2001;11(1):77-93.

106. Laughren T. Memorandum on recommendation for approvable actions for Zyprexa Pediatric Supplements for bipolar disorder (acute mania) and schizophrenia. [pdf from website]. April 29, 2007; Available from:http://www.fda.gov/downloads/Drugs/DevelopmentApprovalProcess/DevelopmentResources/UCM163360.pdf. Published 2010. Accessed Feb 10, 2010.

107. Young RC, Biggs JT, Ziegler VE, Meyer DA. A rating scale for mania: reliability, validity and sensitivity. Br J Psychiatry. 1978;133:429-435.

108. DelBello MP, Cecil KM, Adler CM, Daniels JP, Strakowski SM. Neurochemical effects of olanzapine in first-hospitalization manic adolescents: a proton magnetic resonance spectroscopy study Neuropsychopharmacology. 2006;31(6):1264-1273.

109. Woods SW, Martin A, Spector SG, McGlashan TH. Effects of development on olanzapine-associated adverse events. $J$ Am Acad Child Adolesc Psychiatry. 2002;41(12):1439-1446.

110. Kryzhanovskaya LA, Robertson-Plouch CK, Xu W, Carlson JL, Merida KM, Dittmann RW. The safety of olanzapine in adolescents with schizophrenia or bipolar I disorder: a pooled analysis of 4 clinical trials. J Clin Psychiatry. 2009;70(2):247-258.
111. Ratzoni G, Gothelf D, Brand-Gothelf A, et al. Weight gain associated with olanzapine and risperidone in adolescent patients: a comparative prospective study. J Am Acad Child Adolesc Psychiatry. 2002;41(3): 337-343.

112. Mozes T, Ebert T, Michal SE, Spivak B, Weizman A. An open-label randomized comparison of olanzapine versus risperidone in the treatment of childhood-onset schizophrenia. J Child Adolesc Psychopharmacol. 2006;16(4):393-403.

113. Fleischhaker $C$, Heiser $P$, Hennighausen $K$, et al. Weight gain associated with clozapine, olanzapine and risperidone in children and adolescents. J Neural Transm. 2007;114(2):273-280.

114. Fleischhaker C, Heiser P, Hennighausen $\mathrm{K}$, et al. Weight gain in children and adolescents during 45 weeks treatment with clozapine, olanzapine and risperidone. $J$ Neural Transm. 2008;115(11): $1599-1608$

115. Correll CU, Manu P, Olshanskiy V, Napolitano B, Kane JM, Malhotra AK. Cardiometabolic risk of second-generation antipsychotic medications during first-time use in children and adolescents. JAMA. 2009;302(16):1765-1773.

116. Gebhardt S, Haberhausen M, Heinzel-Gutenbrunner M, et al. Antipsychotic-induced body weight gain: predictors and a systematic categorization of the long-term weight course. $J$ Psychiatr Res. 2009;43(6):620-626

117. Domon SE, Webber JC. Hyperglycemia and hypertriglyceridemia secondary to olanzapine. J Child Adolesc Psychopharmacol. 2001;11(3):285-288.

118. Selva KA, Scott SM. Diabetic ketoacidosis associated with olanzapine in an adolescent patient. J Pediatr. 2001;138(6): 936-938

119. Bloch Y, Vardi O, Mendlovic S, Levkovitz Y, Gothelf D, Ratzoni G. Hyperglycemia from olanzapine treatment in adolescents. J Child Adolesc Psychopharmacol. 2003;13(1):97-102.

120. Courvoisie HE, Cooke DW, Riddle MA. Olanzapine-induced diabetes in a seven-year-old boy. J Child Adolesc Psychopharmacol. 2004;14(4):612-616.

121. Gonzalez-Heydrich J, Raches D, Wilens TE, Leichtner A, Mezzacappa E. Retrospective study of hepatic enzyme elevations in children treated with olanzapine, divalproex, and their combination. J Am Acad Child Adolesc Psychiatry. 2003;42(10):1227-1233.

122. Wudarsky M, Nicolson R, Hamburger SD, et al. Elevated prolactin in pediatric patients on typical and atypical antipsychotics. $J$ Child Adolesc Psychopharmacol. 1999;9(4):239-245.

123. Alfaro CL, Wudarsky M, Nicolson R, et al. Correlation of antipsychotic and prolactin concentrations in children and adolescents acutely treated with haloperidol, clozapine, or olanzapine. J Child Adolesc Psychopharmacol. 2002;12(2):83-91.

124. Kumra S, Jacobsen LK, Lenane M, et al. Case series: spectrum of neuroleptic-induced movement disorders and extrapyramidal side effects in childhood-onset schizophrenia. $J$ Am Acad Child Adolesc Psychiatry. 1998;37(2):221-227.

125. Picard LS, Lindsay S, Strawn JR, Kaneria RM, Patel NC, Keck PE Jr. Atypical neuroleptic malignant syndrome: diagnostic controversies and considerations. Pharmacotherapy. 2008;28(4): $530-535$

126. Neuhut R, Lindenmayer JP, Silva R. Neuroleptic malignant syndrome in children and adolescents on atypical antipsychotic medication: a review. J Child Adolesc Psychopharmacol. 2009;19(4): 415-422.

127. Abu-Kishk I, Toledano M, Reis A, Daniel D, Berkovitch M. Neuroleptic malignant syndrome in a child treated with an atypical antipsychotic. J Toxicol Clin Toxicol. 2004;42(6):921-925.

128. Mendhekar DN, Duggal HS. Persistent amnesia as a sequel of olanzapine-induced neuroleptic malignant syndrome. J Neuropsychiatry Clin Neurosci. 2006;18(4):552-553.

129. Cohen LG, Fatalo A, Thompson BT, Di Centes Bergeron G, Flood JG, Poupolo PR. Olanzapine overdose with serum concentrations. Ann Emerg Med. 1999;34(2):275-278. 
130. Croarkin PE, Emslie GJ, Mayes TL. Neuroleptic malignant syndrome associated with atypical antipsychotics in pediatric patients: a review of published cases. J Clin Psychiatry. 2008;69(7):1157-1165.

131. Delieu JM, Horobin RW, Duguid JK. Exploring the relationship of drug-induced neutrophil immaturity and haematological toxicity to drug chemistry using quantitative structure-activity models. Med Chem. 2009;5(1):7-14.

132. Stubner S, Grohmann R, Engel R, et al. Blood dyscrasias induced by psychotropic drugs. Pharmacopsychiatry. 2004;37 Suppl 1:S70-S78.

133. Elian AA. Fatal overdose of olanzepine. Forensic Sci Int. 1998; 91(3):231-235.

134. Gerber JE, Cawthon B. Overdose and death with olanzapine: two case reports. Am J Forensic Med Pathol. 2000;21(3):249-251.

135. Chue $P$, Singer P. A review of olanzapine-associated toxicity and fatality in overdose. J Psychiatry Neurosci. 2003;28(4):253-261.

136. Antia SX, Sholevar EH, Baron DA. Overdoses and ingestions of second-generation antipsychotics in children and adolescents. $J$ Child Adolesc Psychopharmacol. 2005;15(6):970-985.

137. Chambers RA, Caracansi A, Weiss G. Olanzapine overdose cause of acute extrapyramidal symptoms. Am J Psychiatry. 1998;155(11): 1630-1631.

138. Catalano G, Cooper DS, Catalano MC, Butera AS. Olanzapine overdose in an 18-month-old child. J Child Adolesc Psychopharmacol. 1999;9(4):267-271.

139. Kochhar S, Nwokike JN, Jankowitz B, Sholevar EH, Abed T, Baron DA. Olanzapine overdose: a pediatric case report. $J$ Child Adolesc Psychopharmacol. 2002;12(4):351-353.

140. Theisen FM, Grabarkiewicz J, Fegbeutel C, Hubner A, Mehler-Wex $\mathrm{C}$, Remschmidt H. Olanzapine overdose in children and adolescents: two case reports and a review of the literature. J Child Adolesc Psychopharmacol. 2005;15(6):986-995.

141. Cooper WO, Hickson GB, Fuchs C, Arbogast PG, Ray WA. New users of antipsychotic medications among children enrolled in TennCare. Arch Pediatr Adolesc Med. 2004;158(8):753-759.
142. Aparasu RR, Bhatara V. Antipsychotic prescribing trends among youths, 1997-2002. Psychiatr Serv. 2005;56(8):904.

143. Patel NC, Crismon ML, Hoagwood K, et al. Trends in the use of typical and atypical antipsychotics in children and adolescents. $\mathrm{J} \mathrm{Am} \mathrm{Acad}$ Child Adolesc Psychiatry. 2005;44(6):548-556.

144. Cooper WO, Arbogast PG, Ding H, Hickson GB, Fuchs DC, Ray WA. Trends in prescribing of antipsychotic medications for US children. Ambul Pediatr. 2006;6(2):79-83.

145. Olfson M, Blanco C, Liu L, Moreno C, Laje G. National trends in the outpatient treatment of children and adolescents with antipsychotic drugs. Arch Gen Psychiatry. 2006;63(6):679-685.

146. Aparasu RR, Bhatara V. Patterns and determinants of antipsychotic prescribing in children and adolescents, 2003-2004. Curr Med Res Opin. 2007;23(1):49-56.

147. Alessi-Severini S, Biscontri RG, Collins DM, Kozyrskyj A, Sareen J, Enns MW. Utilization and costs of antipsychotic agents: a Canadian population-based study, 1996-2006. Psychiatr Serv. 2008;59(5):547-553.

148. Constantine R, Tandon R. Changing trends in pediatric antipsychotic use in Florida's Medicaid program. Psychiatr Serv. 2008;59(10): 1162-1168.

149. Rani F, Murray ML, Byrne PJ, Wong IC. Epidemiologic features of antipsychotic prescribing to children and adolescents in primary care in the United Kingdom. Pediatrics. 2008;121(5):1002-1009.

150. Lieberman JA, Tollefson GD, Charles C, et al. Antipsychotic drug effects on brain morphology in first-episode psychosis. Arch Gen Psychiatry. 2005;62(4):361-370.

151. Potter MP, Liu HY, Monuteaux MC, et al. Prescribing patterns for treatment of pediatric bipolar disorder in a specialty clinic. $J$ Child Adolesc Psychopharmacol. 2009;19(5):529-538.
Neuropsychiatric Disease and Treatment

\section{Publish your work in this journal}

Neuropsychiatric Disease and Treatment is an international, peerreviewed journal of clinical therapeutics and pharmacology focusing on concise rapid reporting of clinical or pre-clinical studies on a range of neuropsychiatric and neurological disorders. This journal is indexed on PubMed Central, the 'PsycINFO' database and CAS, and is the official

\section{Dovepress}

journal of The International Neuropsychiatric Association (INA). The manuscript management system is completely online and includes a very quick and fair peer-review system, which is all easy to use. Visit http://www.dovepress.com/testimonials.php to read real quotes from published authors. 